\title{
Perceived economic and behavioural effects of the
} mentally ill on their relatives in Kenya: a case study of the Mathari Hospital

\author{
DM Ndetei', M Pizzo², LI Khasakhala ${ }^{3}$, HM Maru4, VN Mutiso5, FA Ongecha-Owuor ${ }^{6}$, DA Kokonya7 \\ 1University of Nairobi \& Director, Africa Mental Health Foundation (AMHF), Nairobi, Kenya, 2Research Associate, AMHF, \\ ${ }^{3}$ Research Fellow, AMHF, 4Mathari Hospital; Ministry of Health, Kenya; Research Associate, AMHF, ${ }^{5}$ Research Fellow, AMHF, \\ ${ }^{6}$ Coast Provincial General Hospital \& Research Associate, AMHF, ${ }^{7}$ Kakamega Provincial General Hospital \& Research Associate, AMHF
}

\begin{abstract}
Objective: There is no documented evidence in Kenya on relatives' perceptions of economic and behavioural effects of the mentally ill patients and their coping mechanisms. To document what relatives of mentally ill patients perceive to be the economic effects of the patients on the family and how they are affected by and cope with the disturbed behaviours of the patients. Method: This was a cross-sectional descriptive study conducted at the Mathari Psychiatric Hospital. Informed consent was obtained from both the relatives and the patients admitted at the hospital. Data on socio-demographic and economic profiles were obtained from the patients and their relatives. The relatives were interviewed using a structured questionnaire to determine what they perceived to be the economic effects of the mental illness, how the various disturbed behaviours of the mentally ill affected them, and how they coped. The data were analysed using SPSS version 11.5 and results are presented in narratives and tables. Results: One hundred and seventy-five relatives and 107 patients were recruited and interviewed. The patients were younger and better educated but economically less well off than their relatives. The relatives perceived that the mentally ill patients caused financial constraints and that various disturbed behaviours, particularly, verbal and physical aggression and refusal of the patient to take medicine or go to hospital, affected the family in different ways. Different coping mechanisms were used, depending on whether or not the behaviours were intrusive. Conclusion: Mentally ill patients adversely affect their families in diverse ways. There is need for appropriate policy to address the needs of families with mentally ill patients at the family and community levels. However, these must be evidence-based and this calls for further research.
\end{abstract}

Key words: Mental illness; Caregivers; Kenya

Received: 26-11-2007

Accepted: 08-10-2008

\section{Introduction}

In the care of the mentally ill, there has been a shift in emphasis from hospital to community-based care and there is considerable interest in non-institutional treatment regimes for patients with severe and chronic psychiatric illness. Whereas in developed countries, day care units, half-

\section{Correspondence:}

Prof DM Ndetei

University of Nairobi, Kenya \& Director, Africa Mental Health Foundation

(AMHF), P.O. Box 48423-00100 Nairobi, Kenya

E-mail: dmndetei@mentalhealthafrica.com or dmndetei@mail.uonbi.ac.ke way houses or sheltered workshops may be part of their community-based care, none or few of these facilities are available in developing countries, placing the full burden of community care on families. Members of the family thus become the principal caregivers.

Caregivers of mental patients experience both subjective and objective types of burden. ${ }^{1,2}$ Subjective burdens refer to psychological consequences on the family such as the relatives' personal appraisal of the situation, and its perceived severity. Objective burden refers to outwardly measurable demands placed on family members. These include disruption of routines in careers, leisure time and 
households of relatives, financial difficulties, strain on interpersonal relationships, a reduction in social support and physical violence. ${ }^{3,4}$

Kenya is a developing country and although it faces a shortage of human and physical resources, it is rich in social, extended family and cultural resources. Unfortunately, these are on the decline due to a shift from an egalitarian economy and extended family-based social support system to nuclear-based Westernised families. Several studies from Africa have addressed the issue of the burden of care giving on families of mentally ill patients. ${ }^{5-8}$ However, no study has been conducted in Kenya on the subjective and objective dimensions of the burden of care on relatives of psychiatric in-patients. This study aimed to fill the gap in the knowledge of the extent of this burden, and to provide suggestions for possible interventions at both policy and practice levels in the Kenyan context. This aim was achieved by measuring the prevalence and perceived severity of subjective and objective dimensions of burden on relatives of psychiatric in-patients at the Mathari Psychiatric Hospital.

The objectives of this study can thus be summarised as follows:

1) To compare and contrast the socio-demographic characteristics and economic indicators of both relatives and patients;

2) To determine the perceptions of relatives of the effect of mental illnesses on family income prior to the patient's admission;

3) To determine the adverse behaviours of patients, how often they occurred, relatives' perceptions of how they affected the family, and how the family coped with the behaviours; and,

4) To make recommendations for possible policy to mitigate the adverse effects found in this study.

\section{Method}

Site

This was a cross-sectional descriptive study of mentally ill patients and their relatives. The patients were admitted at the Mathari Psychiatric Hospital (Kenya's only national referral psychiatric public hospital) during the month of June 2004. The hospital has a capacity of 600 beds and mainly admits patients from Nairobi, the capital city of Kenya, and its environs (with an estimated population of 5 million). At the time of the study, the hospital was served by seven psychiatrists, two of whom were occupied full-time by administrative duties. The inpatient population includes those suffering from a wide range of psychiatric disorders. These patients are usually admitted when they exhibit disturbed behaviour which relatives at home or community members deem as being uncontrollable. Mathari Hospital serves those who cannot afford private in-patient psychiatric facilities.

\section{Subjects}

The patients who participated in this study formed part of the sample recruited for a larger study which sought to describe the clinical epidemiology of patients admitted at Mathari hospital. ${ }^{9}$ Out of the 691 current in-patients who had been admitted to the hospital prior to and during the study period, those who were visited by their relatives were considered for inclusion in this particular study, as were their relatives.

\section{Sampling technique}

Participants in this study included both patients and relatives. The latter were drawn from those who visited patients admitted to the hospital in the course of the month that the study was conducted i.e. convenience sampling. The relatives recruited were the ones who were considered the primary or secondary caregivers of the patients and who were available at the time of the interviews. Patients had to be capable of attending, understanding and responding to questionnaire items to be included in the study. As a result, violent, extremely agitated and acutely psychotic patients were not included. This may of course have introduced a selection bias, thereby limiting data utility.

\section{Instruments and procedure}

Visiting relatives and patients were invited to take part in clinician-administered interviews to elicit information on their socio-demographic and economic profiles. The relatives were also interviewed about their perceptions of the economic effect of the mental illness on the family as well as the effect of behavioural disturbances by the patients on three dimensions: regularity of occurrence; the severity of effect on the family; and, actions taken to mitigate or cope with the disturbed behaviour. An interview schedule assessing the impact of mental illness was used for family members. ${ }^{10}$ The effects enquired about were those experienced by the relatives who lived with and took care of the patient prior to the patient's admission. The patients and relatives were interviewed separately by interviewers who were not aware of their relationship status. The number of relatives interviewed was higher since for some patients, more than one relative visited.

The interviews were conversational in nature and were not time-limited. An interview guide was used to ensure that all the research questions were addressed and to ensure that information was obtained from the participants in a structured format. There were also focus group discussions (FGD) which lasted an average of one and a half hours, and were held with six groups of relatives each consisting of 6-7 members. An FGD guide was used. The relatives were assured that they were under no obligation to participate, that they could withdraw their participation from the study at any point without explanation, and that should they decline participation, the treatment of the patients would not be affected in any way. No relative declined participation in the interviews as they were willing to discuss their problems with the researcher. Participants were made aware that the goal of the interviews was to capture their individual perspectives; that there were no right answers; that multiple realities existed; and that their personal experience with mental illness was what was being requested and valued. Making the intentions of the activity known and ensuring confidentiality and anonymity optimized disclosure, and therefore enabled participants to be more forthcoming and less prone to giving socially acceptable responses. For relatives who experienced 
communication difficulties due to language problems, a nurse who was well-versed in their language acted as an interpreter. In the interviews, relatives of mentally ill patients were asked to identify the problems they faced and to describe how they attempted to deal with them. The FGDs were held to validate the information collected during the initial interviews as it was necessary to see whether or not these were the areas or issues on which group consensus could be demonstrated.

\section{Ethical Issues}

Research clearance was obtained from the Mathari Hospital Research and Ethics Committee. The patients and their relatives received an explanation on voluntary participation and the right to withdraw from the study at any time. There were no direct personal benefits to the patients and the relatives, except for an in-depth clinical evaluation on the patients (as part of the larger study mentioned earlier). The participants were informed that a clearer understanding of the burden of psychiatric illnesses would be a benefit to others inn their situation and ultimately society in general.

To ensure confidentiality of information, only the inpatient registration numbers were indicated on the questionnaires. The patients' and relatives' questionnaires, whose code was only known to the supervisor, were only matched for clinical purposes at the time of data entry.

\section{Data Analysis}

The data were analysed using SPSS version 1 1.5. The Chi squared $\left(\chi^{2}\right)$ test was used to examine if there were differences between patients and relatives in terms of their socio-demographic characteristics. Descriptive statistics on the economic impact of mental illness and the impact of problematic behaviours were also generated.

\section{Results}

One hundred and seventy-five relatives of 107 patients participated in this study.

\section{Socio-demographic characteristics (Table I)}

Among the patients, two-thirds were male $\left(\chi^{2}=8.981 ; \mathrm{p}=\right.$ 0.003); however, among the relatives there was an equal gender distribution $\left(\chi^{2}=0.207 ; p=0.649\right)$. Almost twice as many patients $\left(\chi^{2}=48.383 ; \mathrm{p}=0.041\right)$ as relatives $\left(\chi^{2}=\right.$ $67.362 ; \mathrm{p}=0.022)$ were aged below 40 years $(80.3 \% \mathrm{vs}$ $46.8 \%)$. More than half of the patients $\left(\chi^{2}=131.624 ; \mathrm{p}=\right.$ $0.000)$ and a quarter of the relatives $\left(\chi^{2}=356.483 ; \mathrm{p}=\right.$ $0.000)$ were single. All the patients had acquired at least primary level (up to eight years) of education whereas $12.0 \%$ of the relatives had not attained any formal schooling.

\section{Economic and relationship status (Table II)}

The relatives were economically better off than the patients with regards to employment status and house-ownership. Most of the patients were economically dependent on a relative as almost two-thirds of relatives were living with a patient. Among the relatives, 40.6\% were siblings of the patients, one third were parents (mothers and/or fathers) and the remainder were spouses and children.

\begin{tabular}{|c|c|c|}
\hline Variables & $\begin{array}{l}\text { Relatives } \\
(n=175)\end{array}$ & $\begin{array}{l}\text { Patients } \\
(n=107)\end{array}$ \\
\hline & \multicolumn{2}{|c|}{$n(\%)$} \\
\hline \multicolumn{3}{|l|}{ Gender } \\
\hline Male & $90(51.4)$ & $69(64.5)$ \\
\hline Female & $84(48)$ & 38 (35.5) \\
\hline Unspecified & $1(0.6)$ & \\
\hline \multicolumn{3}{|l|}{ Age (years) } \\
\hline$<20$ & $3(1.7)$ & $1(0.9)$ \\
\hline $20-39$ & $79(45.1)$ & 85 (79.4) \\
\hline $40-59$ & 65 (37.2) & 18 (16.8) \\
\hline $60-79$ & $12(6.9)$ & $3(2.8)$ \\
\hline $80+$ & $1(.6)$ & - \\
\hline Unspecified & $15(8.6)$ & - \\
\hline \multicolumn{3}{|c|}{ Marital status } \\
\hline Single & $43(24.6)$ & $63(58.9)$ \\
\hline Married & 116 (66.3) & 26 (24.3) \\
\hline Widowed & $7(4.0)$ & $5(4.7)$ \\
\hline Divorced & $2(1.1)$ & $2(1.9)$ \\
\hline Separated & $5(2.9)$ & $5(4.7)$ \\
\hline Cohabiting & $1(0.6)$ & - \\
\hline Unspecified & $1(0.6)$ & $6(5.6)$ \\
\hline \multicolumn{3}{|c|}{ Education level } \\
\hline None & $21(12.0)$ & - \\
\hline Primary & $61(34.9)$ & 37 (35.6) \\
\hline Secondary & $69(39.4)$ & $59(56.7)$ \\
\hline Tertiary/college & $19(10.9)$ & $8(7.7)$ \\
\hline Unspecified & $5(2.9)$ & $3(2.8)$ \\
\hline
\end{tabular}

Table II: Economic Status and Relationship between Relatives and Patients

\begin{tabular}{|l|l|l|}
\hline Variables & $\begin{array}{l}\text { Relatives } \\
(n=175)\end{array}$ & $\begin{array}{l}\text { Patients } \\
(n=107)\end{array}$ \\
\hline \multicolumn{2}{|c|}{$n(\%)$} \\
\hline Working status & & \\
Full - time & $72(41.1)$ & $29(27.1)$ \\
Part - time & $19(10.9)$ & $20(18.7)$ \\
Retired & $13(7.4)$ & - \\
Never employed & $15(8.6)$ & $13(12.1)$ \\
Unemployed & $30(17.1)$ & $6(5.6)$ \\
Unspecified & $26(14.9)$ & $39(36.4)$ \\
Housing situation & $78(44.6)$ & $35(32.7)$ \\
Living in own house & $27(15.4)$ & $31(29.0)$ \\
Living in relative's house & $68(38.9)$ & $34(31.8)$ \\
Renting & $2(1.1)$ & $7(6.5)$ \\
Unspecified & & \\
Living with patient? & $107(61.2)$ & \\
Yes & $65(37.1)$ & \\
No & $3(1.7)$ & \\
Unspecified & & \\
Family membership status & $25(14.3)$ & $30(28.0)$ \\
Father & $33(18.8)$ & $24(22.4)$ \\
Mother & $10(5.7)$ & $9(8.4)$ \\
Husband & $10(5.7)$ & $10(9.3)$ \\
Wife & $71(40.6)$ & $20(18.7)$ \\
Brother/sister & $7(4.0)$ & $7(6.5)$ \\
Son/daughter & $19(10.9)$ & $3(2.8)$ \\
Other & - & $4(3.7)$ \\
Unspecified & & \\
\hline
\end{tabular}




\section{The perceived economic effect of the mental illness on the family (Table III)}

The results presented are only pertinent to those relatives who answered in the affirmative and provided details of the degree of impact of the mental illness in their responses. Relatives reported that family finances suffered the greatest impact due to the patients' mental illness. Significant proportions of the relatives responded in the affirmative to items that concerned family income.

\section{Problematic behaviours, their effects and coping mechanisms (Table IV)}

The problematic behaviours that occurred with the greatest regularity among the patients included misuse of alcohol $(27.2 \%)$ and wandering (20.2\%). Wandering, verbal aggression, disturbance of family at night, misuse of alcohol, physical aggression, refusal to go to hospital and being unreliable were the behaviours that caused quite a lot of effect on between $40 \%$ and $53.8 \%$ of the relatives. Although a high proportion of relatives reported that patients becoming physically violent occurred only on certain occasions, it was one of the behaviours that had quite a lot of effect on the family.

The use of prayer as a coping mechanism by relatives was reported uniformly for all problematic behaviours in patients. Behaviours such as 'lack of conversation', 'keeping to oneself' and 'not doing anything' were ignored by half of the relatives. Force/restraint was used more often than any other action to take patients to hospital and to make them take their medicine. External help was sought mainly in dealing with physical aggression (68.1\%), wandering (48.3\%), destruction of property (44.0\%) and taking the patient to hospital (43.3\%). The behaviours for which the least number of relatives asked for help were the same ones which were simply ignored. Helplessness (not knowing what to do) was reported in the case of alcohol misuse (by about one-third of the relatives), unreliable behaviour, doing things slowly (25.2\%) and verbal aggression (20.5\%).

\section{Table III: The Economic Effects of the Mental IIIness on the Family}

\begin{tabular}{|c|c|c|c|c|}
\hline Type of effect (As perceived by the relatives prior to patient's admission $N=175$ ) & Mild & Moderate & Severe & Extremely severe \\
\hline & \multicolumn{4}{|c|}{$n(\%)$} \\
\hline $\begin{array}{l}\text { 1. Has the patient lost her/his job due to illness? }(n=26)^{\star} \\
\text { To what extent has it affected the family? }\end{array}$ & $19(41.3)$ & $14(30.4)$ & $8(17.4)$ & $5(10.9)$ \\
\hline $\begin{array}{l}\text { 2. Did any member of the family stop working due to the patient's illness? } \\
(\mathrm{n}=36) \\
\text { To what extent has it affected the family? }\end{array}$ & $9(25)$ & $11(30.6)$ & $12(33.3)$ & $4(11.1)$ \\
\hline $\begin{array}{l}\text { 3. Is any member of the family working part-time due to the patient's illness? } \\
(\mathrm{n}=37) \\
\text { To what extent has it affected the family? }\end{array}$ & $19(51.4)$ & $8(21.6)$ & $6(16.2)$ & $4(10.8)$ \\
\hline $\begin{array}{l}\text { 4. Does any member of the family sometimes miss work due to the patient's } \\
\text { illness? }(\mathrm{n}=37) \\
\text { How does it affect her/his work? }\end{array}$ & $19(51.4)$ & $8(21.6)$ & $6(16.2)$ & $4(10.8)$ \\
\hline $\begin{array}{l}\text { 5. Has the patient's treatment affected the family's income? }(\mathrm{n}=134) \\
\text { To what extent has it affected the family's income? }\end{array}$ & $13(9.7)$ & $57(42.5)$ & $41(30.6)$ & $23(17.2)$ \\
\hline $\begin{array}{l}\text { 6. Has the family spent money in repairing property destroyed by the patient? } \\
(\mathrm{n}=64) \\
\text { To what extent has it affected the family? }\end{array}$ & $14(21.9)$ & $13(20.3)$ & $23(35.9)$ & $14(21.9)$ \\
\hline $\begin{array}{l}\text { 7. Has the family spent money reimbursing other people whose property has } \\
\text { been damaged by the patient? }(n=175) \\
\text { How often does it happen? }(n=51)\end{array}$ & $11(21.6)$ & $15(29.4)$ & $13(25.5)$ & $12(23.5)$ \\
\hline $\begin{array}{l}\text { 8. Does the patient need money for transport to attend clinic? }(n=163) \\
\text { To what extent is it a problem? }\end{array}$ & $9(5.5)$ & $86(52.8)$ & $52(31.9)$ & $16(9.8)$ \\
\hline $\begin{array}{l}\text { 9. Have you made extra arrangements for someone to look after the patient? } \\
(\mathrm{n}=58) \\
\text { To what extent has it affected the family? }\end{array}$ & $27(46.6)$ & $19(32.8)$ & $8(13.8)$ & $4(6.9)$ \\
\hline 10. Is the patient receiving disability pension? $(n=8)$ & & & & \\
\hline
\end{tabular}




\begin{tabular}{|c|c|c|c|c|c|c|c|c|c|}
\hline \multirow[b]{2}{*}{ Behaviour } & \multicolumn{2}{|c|}{ Regularity } & \multicolumn{2}{|c|}{ Level of effect on family } & \multicolumn{5}{|c|}{ Action taken by relatives } \\
\hline & Sometimes & Always & Moderately & Quite a lot & Pray & Ignore & $\begin{array}{l}\text { Restraint/ } \\
\text { force }\end{array}$ & Ask for help & $\begin{array}{l}\text { Don't know } \\
\text { what to do }\end{array}$ \\
\hline 1. Wandering & 29.5 & 20.2 & 21.5 & $53.7^{*}$ & 11.0 & 18.6 & 16.9 & 48.3 & 5.1 \\
\hline 2. Refuses medicine & 36.4 & 9.9 & 22.2 & 37.6 & 16.5 & 7.3 & 37.6 & 35.8 & 2.8 \\
\hline 3. Refusal to go hospital & 23.8 & 12.2 & 9.3 & 43.9 & 22.7 & $3.1^{*}$ & 27.8 & 43.3 & 3.1 \\
\hline 4. Lack of conversation & 27.7 & 6.6 & 23.0 & 11.9 & 23.1 & 54.7 & 5.1 & 7.7 & 9.4 \\
\hline 5. Keeps to himself & 30.1 & 9.8 & 19.6 & 10.7 & 17.4 & 56.4 & 9.4 & 9.4 & 6.7 \\
\hline 6. Not doing anything & 40.5 & 17.3 & 28.5 & 29.9 & 20.0 & 52.8 & 9.6 & 8.0 & 9.6 \\
\hline 7. Slow doing things & 38.7 & 15.0 & 23.8 & 15.0 & 22.6 & 21.3 & 13.5 & 17.4 & 25.2 \\
\hline 8. Unreliable & 23.1 & 17.3 & 17.6 & 40.3 & 24.5 & 27.4 & 0.9 & 17.0 & 30.2 \\
\hline 9. Disturbs family at night & 25.4 & 12.1 & 15.3 & 48.4 & 26.5 & 24.8 & 3.4 & 30.8 & 14.5 \\
\hline 10. Noisy, shouts & 31.8 & 11.6 & 17.4 & 33.3 & 17.3 & 34.6 & 3.1 & 26.0 & 18.9 \\
\hline 11. Swears, rude to people & 39.3 & 13.1 & 12.9 & $53.8^{*}$ & 26.8 & 19.7 & 5.5 & 27.6 & 20.5 \\
\hline 12. Laughs, talks to self & 33.9 & 5.8 & 19.4 & 28.0 & 21.5 & 40.0 & 9.2 & 20.0 & 9.2 \\
\hline 13. Neglects personal hygiene & 36.3 & 14.0 & 10.7 & 32.8 & 28.5 & 26.2 & 18.5 & 23.1 & 3.8 \\
\hline 14. Embarrassing in appearance & 35.7 & 9.9 & 12.1 & 30.7 & 26.1 & 29.1 & 12.7 & 26.1 & 6.0 \\
\hline 15. Aggressive, hits people & $45.6^{\star}$ & 6.4 & 19.5 & 44.2 & 15.6 & 9.6 & 2.2 & $68.1^{\star}$ & 4.4 \\
\hline 16. Destroys property & 24.0 & 6.4 & 16.7 & 36.8 & 27.4 & 10.7 & 6.0 & 44.0 & 11.9 \\
\hline 17. Misuse alcohol etc & 22.8 & $27.2^{*}$ & 25.7 & 48.7 & 20.0 & 18.9 & 4.2 & 25.3 & $31.6^{\star}$ \\
\hline
\end{tabular}

\section{Negative effects of patients' illness on the family}

Economic inputs (work/employment and income/finances), suffered the greatest impact of the illness, followed by relationships (household interactions and relationship with children) and then social life.

\section{First contacts and distances covered}

Traditional and faith healers constituted $5.8 \%$ of all first contacts. Health centres were visited by $91.4 \%$ of the relatives as the first point of contact for consultation. Distances covered in the search for health services ranged between less than 5 kilometres (3. 1miles) (for $24.6 \%, n=43$ of the relatives) and more than 100 kilometres (62.1 miles) (for 11 or $6.3 \%$ of the relatives)

\section{Discussion}

The study suffers from a number of limitations, specifically related to the lack of a validated instrument for measuring the burden of care amongst family members as well as the potential exclusion of patients most burdensome. However, the intention of this study was to provide baseline data as a basis for policy-oriented awareness and possible action including further research. The findings of this study can thus be discussed with the above caveats in mind.

The finding that there were more male than female patients is reflective of a disproportionate allocation of beds at Mathari Hospital. This in itself is an illustration of higher rates of admission for males than for females possibly as a result of greater societal intolerance to physically aggressive males compared to females. It could also be as a result of real differences in experience of mental illness according to gender, and particularly, of disturbed behaviours resulting thereof. On the other hand, there were no significant differences in the gender distribution of relatives, with more or less similar numbers of male and female relatives, recorded.

Patients were generally younger than the relatives (80\% vs $46 \%$ aged less than 40 years) and this was also reflected in the fact that many were single. This finding can be explained in several ways. The most plausible explanation is that the onset of mental illness generally occurs at a relatively younger age. The younger population in Kenya 
also happens to be better educated particularly since recently, there are more opportunities for education. Those who are older and more economically stable take the responsibility of caring for the behaviourally-disturbed mentally ill patients. Relatives were economically better off than patients and this was reflected in their working status and home ownership, although it is possible that mental illness may have contributed to lower economic status in the patients in general. These trends suggest a dependence of the patients on their relatives in an environment where there is no welfare support system.

The most common relationships between the patients and visiting relatives were parental or sibling rather than marital, a finding which was not surprising given that the patients were relatively young and single. In summary, the socio-demographic and economic profiles of the patients in relation to their relatives showed a younger, somewhat better educated patient population that was economically dependent on an older more economically empowered relative (parent or sibling).

Mental illnesses had economic effects that were detrimental to the family status in several ways. When the patient lost a job as a result of the illness, s/he ended up becoming dependent on the relative. When the relative stopped working or reduced their working hours in order to take care of the patient, the family's financial status worsened. The family's financial resources were also diverted into caring for the patients or paying for expenses incurred directly by the patients through damage of property. Family finances were also affected when money was used to meet the costs of transporting the patients for treatment in facilities, some of them as far as 50 kilometres away. Payment for damage caused by the patients and costs of treatment were cited by most relatives and this showed that the effects were widespread.

All of these economic effects were experienced within a context where the population was already poor and who, without the additional economic burden of mental illness, lived on less than US $\$ 1$ per day, and who hardly received any disability support at home or for transport to health facilities. It is therefore not surprising that for the 134 relatives who responded positively on Item 5 in Table IV, $87 \%$ reported moderate to extremely severe economic effects as a result of the mental illness in the patients. This finding was similar to findings of an Ethiopian rural community-based study involving 301 patients with schizophrenia and their close relatives where financial difficulty was the most frequently endorsed problem (74.4\% of the cases) among the family burden domains across both sexes. ${ }^{7}$ However, gender differences were seen in financial and work burden domains with female relatives reporting being more affected than male relatives. Several other studies have also reported financial difficulties as mental illness had a negative effect on the income of the family. ${ }^{3,4,11}$

The different problematic behaviours occurred with fairly similar regularity but their effects on the family were not uniform. Non-intrusive behaviours such as 'lack of conversation', 'keeping to oneself' and 'slow in doing things' had the least effect on the family, whereas intrusive behaviours, particularly, verbal and physical aggression, affected the family the most. This finding corroborates what was reported in other studies where disorganised symptoms rather than (primary features of) the actual diagnosis (as classified by the fourth edition of the Diagnostic and Statistical Manual for Mental Disorders [DSM-IV]) ${ }^{12}$, were the most important factors affecting family members in all family burden domains. ${ }^{6,7,11}$ Abuse of alcohol by mentally ill patients may have led either to misuse of badly needed family resources or to unacceptable behaviour while under the influence of alcohol. Behaviours that were exhibited beyond the confines of the home, for example, wandering, may have posed a threat to the patient and others outside the family. Of special note among the behaviours that caused 'quite a lot of effect' on the family were those directly related to treatment i.e. refusal to take medicine and to go to hospital for treatment. This suggested that relatives were willing and determined to ensure that the mentally ill patients were cared for and got better. This speculation is illustrated in the findings of a Nigerian study which reported that despite the high levels of burden experienced, families expressed the wish to continue caring for their relatives in the communities. ${ }^{8}$ Since caregiving to mentally ill patients can also lead to positive and rewarding experiences on the part of relatives, it is therefore not always exclusively burdensome. ${ }^{13}$

The action taken by relatives was generally reflective of the level of effect on the family and different coping strategies were used. Scazufca and Kuipers ${ }^{14}$ who also studied coping strategies in relatives of people with schizophrenia reported that majority of relatives used a variety of strategies to cope with the demands imposed by the patients. The coping strategies adopted were influenced by available psychological, social, cultural and practical resources. ${ }^{15}$ Prayer was used uniformly to cope with all kinds of behaviour as has been reported in another study where prayer was most frequently used as a coping strategy. ${ }^{7}$ This finding was not surprising given that a large proportion of the Kenyan population prescribes to some kind of faith, although religious affiliation was not enquired for in this particular study. Non-intrusive behaviours were largely ignored whereas force was used to ensure treatment was sought and adhered to, in the best interest of the patients. External help was sought by relatives most often when the behaviours exhibited were intrusive e.g. wandering, physical aggression and destruction of property. Nearly onethird of the relatives did not know what to do with unreliable and alcoholic patients, and this may have been because they had tried other means of coping with these behaviours, with no success.

Visiting health facilities was a common first recourse for help although traditional and faith healers were also visited but with less frequency. It is most likely that the use of traditional and faith healers was under reported, as it has been shown that people with psychiatric disorders use both hospital-based services as well as traditional services. ${ }^{16}$ Perhaps this finding was missed because this study enquired for first contact for help. It is probable that even after making the first contact with medical facilities, patients and relatives also subsequently consulted traditional healers.

The overall effects of the patients' illnesses on the relatives were felt in the domain of economic burden and any intervention policies should be targeted towards 
mitigating the adverse economic effects suffered by families with mentally ill patients. As observed by another study, since relatives continue to play a caregiving role for patients experiencing a mental illness, there is need to focus on specific interventions that would reduce their high levels of distress and burden. ${ }^{8}$ At the same time, the emotional and social impact of the mental illness on children in particular, and the family as a whole should be addressed, given that mental illness has been found to have a detrimental effect on children. ${ }^{4,17}$ Other studies have suggested that even in a society with strong family networks, family psychoeducation on the nature of mental illness and dealing with its stigma and family burdens be used as an intervention. ${ }^{\text {? }}$

\section{Conclusion}

Community facilities that take services to the families will reduce the costs of travelling, provide psycho-education on how to deal with and minimize the effects of problematic behaviours, and educate members on how to reduce stigmatisation of the mentally ill. This education, coupled with family therapy, will go a long way in mitigating the effects of the mentally ill on their families, and particularly children. Such a programme, in a context where financial and human resources are limited, calls for a revised approach to mental health service provision. A scaling up of the mid-level cadres in the area of mental health, and in the training of lay community health workers will go a long way in addressing the shortage. ${ }^{18}$ The onus will be on these midlevel cadres to identify and manage most mental health disorders in the community and only refer the most complicated cases. Amongst these community-based approaches may be a constructive engagement and education of traditional healers who, as has been illustrated, see most of the patients with mental illness in the communities. ${ }^{19}$

Besides highlighting a community- and family-oriented inclusive approach to the management of the mentally ill, this study underscores the deficiencies in the current practice of patient-focussed management and prescription of drugs outside the patient's context. Though family and community support may be common practice in developed countries, this study provides contextual evidence that the same can and must be adopted as part of policy and practice in Kenya and other similar contexts. However, this can only be implemented if evidence for the most effective community approach and mobilisation of resources is adduced through further research.

\section{Acknowledgement}

The Africa Mental Health Foundation (AMHF) provided administrative support for this study. The authors would like to thank Grace Mutevu of AMHF for analysis of the data and in the preparation of the paper, and Patricia Wekulo for editing the paper.

\section{References}

1. Platt S. Measuring the burden of psychiatric illness on the family: an evaluation of some rating scales. Psychol Med 1985; 15: 383-393.

2. Schene AH, Tessler RC, Gamache GM. Caregivers in Severe Mental Illnesses: Conceptualisation and Measurement - Mental Health Service Evaluation. University Press, Cambridge, 1996.

3. Clausen JA, Yarrow MR. The impact of mental illness on the family. J Soc Issues 1955; 11:3-11.

4. Grad J, Sainsbury P. Mental illness and the family. Lancet 1963; 9:544548.

5. Ohaeri JU, Fido AA. The opinions of caregivers on aspects of schizophrenia and major affective disorders in a Nigerian setting. Soc Psychiatr Psych Epid 2001; 36 (10): 493-499.

6. Ohaeri JU. Caregiver burden and psychotic patients' perception of social support in a Nigerian setting. Soc Psychiatr Psych Epid 2001; 36 (2): 86-93.

7. Shibre T, Kebede D, Alem A, Negash A, Deyassa N, Fekadu A et al. Schizophrenia: illness impact on family members in a traditional society - rural Ethiopia. Soc Psychiatr Psych Epid 2003; 38 (1): 27-34.

8. Ukpong DI. Demographic factors and clinical correlates of burden and distress in relatives of service users experiencing schizophrenia: A study from south-western Nigeria. Int J Mental Health Nurs 2006; 15 (1): 54-59.

9. Ndetei DM, Khasakhala LI, Maru H, Pizzo M, Mutiso V, OngechaOwuor FA, Kokonya DA. Clinical epidemiology in patients admitted at Mathari psychiatric hospital, Nairobi, Kenya. Soc Psychiatr Psychiatric Epidemiol 2008; 43 (9): 736-742.

10. Mthoko NFN. The perceived impact of a relative's mental illness on family members and their reported coping responses: A Namibian study. [Masters dissertation]. University of Zimbabwe: Harare; 2001.

11. Whyte SR. Family experiences with mental health problems in Tanzania: A survey of treatment histories and social situations. Acta Psychiatr Scand 1991; 83 (suppl. 364): 77-111.

12. American Psychiatric Association. Diagnostic and Statistical Manual of Mental Disorders, 4th Edition: (DSM-IV). American Psychiatric Press, 1994.

13. Ohaeri JU. The burden of caregiving in families with a mental illness: a review of 2002. Curr Opin Psychiatry 2003; 16 (4): 457-465.

14. Scazufka M, Kuipers E. Coping strategies in relatives of people with schizophrenia before and after psychiatric admission. Br J Psychiatry 1999; 174: 154-158.

15. Perlin LI, Schooler C. The structure of coping. J Health Soc Beh 1978; 19: 2-21.

16. Otsyula $W$, Rees PH. The occurrence and recognition of minor psychiatric illness among outpatients at the Kenyatta National Hospital, Nairobi. East Afr Med J 1972; 49 (1 1): 825-829.

17. Grad J, Sainsbury P. The effects that patients have on their families in community care and control psychiatric service - a two year follow up. Br J Psychiatry 1968; 1 14: 265-278.

18. Ndetei DM, Ongecha FA, Mutiso V, Kuria M, Khasakhala LI, Kokonya $D A$. The challenges of human resources in mental health in Kenya. $S$ Afr Psychiatr Rev 2007; 10: 33-36.

19. Otsyula W. Native and Western healing: the dilemma of East African Psychiatry. J Nervous Ment Dis 1973; 156: 297-299. 